\title{
COMPUTER SIMULATION OF INNOVATION IMPLEMENTATION STRATEGIES
}

Peter S. Hovmand

\author{
School of Social Work \\ Washington University in St. Louis \\ St. Louis, MO 63130 USA
}

\author{
David N. Ford \\ Department of Civil Engineering \\ Texas A\&M University \\ College Station, TX 77843-3136 USA
}

\begin{abstract}
Many interventions that are effective in one setting may be ineffective or even harmful in other settings. This poses a problem for organizations and communities planning the implementation of new programs, policies, and practices. This paper introduces the use of system dynamics computer simulation of real options to design implementation strategies in complex social systems. The approach is illustrated with an example of domestic violence community interventions involving the implementation coordination and victim advocacy to reduce the unintended consequence of victim arrests from a mandatory arrest policy. Results show that there are potential benefits to using a real options approach.
\end{abstract}

\section{INTRODUCTION}

The effectiveness of community interventions often vary between communities. What works in one community, for example, may be ineffective or even harmful in other communities. Typical explanations for these differences include complex interactions between demographics, availability of resources and services, local governance structure, cultural norms, and geography among others. For any organization or community seeking to address social problems, these interactions introduce uncertainty into the process of implementing interventions: Will this work in our community? Can we implement this successfully given our training and resources? Can we develop sufficient stakeholder support for the implementation process? Do the potential benefits outweigh the risks of deploying an ineffective intervention? What do we do if it isn't working? How do we tell the difference between an intervention that isn't working and intervention that just needs more time to be implemented?

One way to reduce the uncertainty is to conduct more research, but this presupposes that there is some underlying generalizable phenomenon across communities, and sufficient time and resources to discover it. Most communities cannot wait to respond to pressing social problems, and therefore make do with the limited information available and make planning and implementation decisions under conditions of bounded rationality (Kahneman, Slovic, and Tversky 1982).

Forcing a "solution" onto a community with uncertain impact raises its own challenges, especially if stakeholders have divergent views on the potential benefits or harm to the community. For example, in the area of community responses to domestic violence, some stakeholders may view mandatory arrest policies with deep suspicion because of the potential to exacerbate racial disparities, while others see it as necessary intervention to protect women. In some cases, these challenges can effectively block the implementation of any solution and bring efforts to address a social problem to a halt. Thus, even if an intervention is adopted by the community it might not be fully implemented because stakeholders resist its implementation. For example, domestic violence shelters might not cooperate with police, or police might pursue criminal cases against the victim of domestic violence despite the protest of the victim advocates. In some cases, these types of conflicts can literally result in standoffs between law enforcement and victim advocates. Is there a better way to manage this type uncertainty for communities seeking to implement interventions?

This paper takes up this question by exploring the use of real options analysis (e.g., Dixit and Pindyck 1994) to develop strategies for implementing community interventions. The idea of real options comes from corporate finance and provides a way to think more rationally about capital investment decisions when there is significant uncertainty about the potential benefits. A real option is the right to pursue some specific course of action in the future without the obligation to exercise that right (Dixit and Pindyck 1994). For example, a company might purchase land next to an existing manufacturing facility. In purchasing the land, the company is creating an option to expand, but it is not obligated to do so if market conditions do 


\section{Hovmand and Ford}

not warrant such investments. Purchasing the land gives the company flexibility and a means to manage the uncertainty of future expansion needs. The main idea behind real options analysis is that this flexibility has a value not captured by a cost/benefit analysis. Options include certain specific features that distinguish them from other types of strategies. Of particular importance is that all options include delaying a choice between two or more strategies while an uncertainty is reduced to improve the strategy choice. Some refer to this as a form of learning. This feature (and others) distinguish options from other strategy alternatives. For example, a strategy that allows one to purchase asset A now or asset B now under uncertainty about their future performances has two alternatives but no options since there is no delayed decision making for learning.

While real options analysis in corporate finance generally focuses on the valuation of investment strategies in terms of monetary outcomes, Ford and Sobek (2005) have extended the approach to include non-monetary outcomes in a comparison of two product development strategies, and then used the approach to help explain the second Toyota Paradox. To avoid confusion with traditional corporate finance, Ford refers to this use of real options in managerial decision making as managerial real options. Hence, for the remainder of the paper, by real options we mean managerial real options and will be explicit when distinguishing managerial real options from other uses of options.

In this paper, we therefore develop an approach for modeling a managerial real options approach to evaluate strategies for implementing community interventions. We demonstrate the approach using an earlier system dynamics model of the implementation of mandatory arrest policies and its unintended consequences on victim arrests (Hovmand and Ford in press; Hovmand, Ford, Flom, and Kyriakakis 2007; Hovmand, Ford, Flom, and Kyriakakis in press). Using this model, we then consider the following two questions:

1. How viable is the use of a managerial real options approach for developing strategies for implementing community interventions?

2. What is the added value of combining system dynamics modeling with a managerial real options approach?

\section{BACKGROUND}

This paper is both exploratory and interdisciplinary in drawing on knowledge system dynamics, corporate finance, implementation science, and community psychology, and applying it to mandatory arrest policies in domestic violence as an example of a community level social interventions. This requires some background in making the connections, so in this section we provide an overview of what we mean by implementation strategies, managerial real options, and the application area of mandatory arrest policies in domestic violence.

\subsection{Adoption, Implementation, and Implementation Strategies}

In implementation science, there is often a distinction drawn between the diffusion, dissemination, adoption, and implementation of innovations. Diffusion is often characterized as the natural unsystematic process by awareness of the innovation spreads from one actor to another actor (e.g., word of mouth effects), dissemination as the systematic efforts for getting information about the innovation to potential adopters and users (e.g., targeted outreach efforts to communities), adoption as the decision to implement an innovation (e.g., writing a new agency policy), and implementation as the actual use of the innovation as intended (e.g., using an intervention as intended).

These distinctions have become important in implementation science, especially in health care and social interventions, where there are often long delays between when a proven intervention is known and its routine use in some system. As a consequence, only a small fraction of knowledge about social and health interventions is actually in use and available to potential beneficiaries. The process of moving innovations from their initial discovery to regular use can break down at any step in the process. While there is a tendency to think that more marketing will solve the problem, it is often the case that we are aware of the benefits from an intervention, but often fail to actually use it. Klein and Knight (2005) draw attention to this in the difference between adoption and implementation with an example of exercise equipment: adoption is the purchase of the exercise machine, implementation is its actual use as intended. These distinctions have also become important in management. For example, Pfeffer and Sutton (2000) describe the challenges that organizations face in implementing what they know to be good business practices as the knowing-doing gap.

One area that has drawn increasing attention in recent years has been the actual process of implementing innovations. The implementation of innovation is inherently dynamic and often fraught with dynamic complexity. For example, Samuel and Jacobsen (1997) used system dynamics to help explain the worse-before-better in planned organizational change and the importance of including stakeholders in the planning process for complicated innovations. Repenning (2002) showed how the durability of managerial commitment could be a critical factor in the success or failure of an implementation process with 


\section{Hovmand and Ford}

known benefits to the organization. Hovmand and Gillespie (2008) examined how organizational characteristics influenced improvement in performance after implementing an innovation, and found that only the most efficient organizations improved in performance from implementing the innovation. These efforts highlight the challenges of managing the implementation process, and draw attention to the need to develop better strategies for implementing innovations in organizations and communities.

An implementation strategy is specified set of activities designed to put into practice an innovation of known dimensions (Fixsen et al. 2005, Proctor et al. 2009). An "innovation of known dimensions" is one that has explicit criteria for whether or not it is being implemented. This is important for there is often drift or adaptation of the intervention as it is implemented. In some cases, the changes can make the innovation essentially unrecognizable even though its users claim to be implementing the innovation. In community interventions, the set of activities comprising an implementation strategy may include training of professionals, community planning and coordination meetings, the development and installation of new information technology systems for managing and tracking information, new policies, evaluation systems, oversight mechanisms, new laws, new professional positions, and raising funds to support these efforts. When multiple interventions are involved, each can have its own set of activities.

\subsection{Managerial Real Options}

Central to any managerial real options approach is the identification of an option, that is, a choice to pursue some action at a later time. This option may be the ability to implement an intervention such as a new law or prevention program, the ability to switch from one intervention to another intervention, or the ability to discontinue an intervention after it has been implemented.

Associated with the option is an exercise decision. This exercise decision defines when the course of action is to be pursued. For example, the exercise decision defines how one decides whether or not to implement an intervention, switch to a new intervention, or discontinue an intervention. The exercise decision is defined in terms of an exercise signal, i.e., a variable that is monitored and then evaluated according some formal criterion. In the classic example of stock options, the exercise decision would be to sell a stock if it falls below a certain price, and the exercise signal would be the stock price. In the managerial real options approach one needs to both define the exercise decision and the exercise signal in the context of some set of observable variables.

Managerial real options become interesting when the option "costs" something. However, options become more complicated to evaluate when we give something up in exchange for having the option. The option cost is what we have to "pay" for the option. In real options, the option cost might be the land purchase plus taxes and fees associated with the land purchase. In the managerial real options approach, we need to consider what the corresponding costs might be. In a community intervention, for example, the costs might include opportunity costs (e.g., people who could have been helped with another intervention) or training costs.

Evaluating the benefit of managerial option involves comparing the managerial real options strategy against a reference strategy with no options. The reference strategy is the strategy we would follow without a real options approach, and the alternative strategy is the strategy using a managerial real options approach. The difference between these two strategies on one or more performance measures is the value of the option.

The actual comparison must be made on some set of performance measures. In corporate finance, this would normally be the monetary return on investment. In the managerial real options approach, the performance measure needs to be defined with respect to the problem at hand. In the case of product development, for example, the performance measures could be the length of the development cycle and having the best technology. In the community intervention example, it could be the community level outcomes.

Each of these concepts must be formally defined for the managerial real options approach. In fact, one of the interesting aspects of this approach is that it forces one to more carefully consider the structure of decision making as it relates to the implementation strategy, and consider a variety of costs and performance measures when evaluating strategies.

\subsection{Mandatory Arrest Policy}

To illustrate the real options approach to implementing community interventions, we consider the introduction of a domestic violence arrest policy. A thorough discussion of the issues surrounding domestic violence arrests is beyond the scope of this paper, and the reader is referred elsewhere (Avakame and Fyfe 2001, Bracher 1996, Eigenberg et al. 2003, Eitle 2005, Hirschel and Buzawa 2002, Hirschel and Hutchison 2003, Mignon and Holmes 1995, Mills 1998, Wanless 1996). However, a brief overview of the issue is will help set the stage for the example in this paper and why this is good example for considering other types of social interventions. 


\section{Hovmand and Ford}

Prior to the 1980's in the United States, the criminal justice response to domestic violence was characterized as a "laissez faire" approach. Sherman and Berk (1984) then published their results from their landmark Minneapolis experiment looking at the specific deterrent effects of arrest on domestic violence. They found that arrest did deter domestic violence recidivism. Based on these results combined with legal cases against police departments for failing to protect victims from their abusers, many communities began adopting and then implementing what became known as pro and mandatory arrest policies. In pro arrest policies, police officers are encouraged to make an arrest for domestic violence if they saw signs of domestic abuse (e.g., bruises on the victim, broken furniture). In mandatory arrest policies, they are required to make an arrest. By 2000, nearly $90 \%$ of police departments in the United States had written pro or mandatory arrest policies. However, an unintended consequence from the implementation of these policies was the increase in arrests of primary victims. Today approximately $20 \%$ of domestic violence arrests involve the arrests of the primary victim (Durose et al. 2005, Hirschel and Buzawa 2002). This has created considerable controversy about the effectiveness of criminal justice interventions for domestic violence, and raised major questions about how to implement community responses to domestic violence, and whether coordinated efforts should even be attempted given the potential for risks.

A system dynamics model was developed to understand the increase in victim arrests (Hovmand et al. 2007). Analysis of the model showed how different feedback mechanisms contributed to increase and decline in primary victim arrests (Hovmand et al. in press), and how the relationships between the sequence and timing of multiple community interventions affected outcomes (Hovmand and Ford in press). Follow-up analyses suggested that multiple interventions were needed to achieve the best outcomes, but simultaneous implementations of multiple interventions were less effective than a sequenced implementation strategy. Results showed a complex interaction between the sequence and timing of intervention strategies including the presence of local minima and maxima in outcomes that would be difficult for a coordinating council to navigate effectively. For example under some conditions, it would be better to wait to implement an intervention while other conditions would favor a implementing the intervention as soon as possible. Such interactions introduce significant uncertainty into the implementation of interventions since decision makers often do not know what state the system is in prior to implementation, if the interventions will work with a specific population, and delays in the implementation process can be hard to control.

The problem of victim arrests from implementing mandatory arrest policies represents a good model for considering the application of a real options approach. First, it highlights a real world example where the purported benefits of an empirically tested intervention had unintended consequences and created significant controversy across many communities in the United States. One might wonder if this is an exceptional case and whether one might not simply test the intervention more thoroughly, but alas most community interventions are tested much less thoroughly because they tend to be prohibitively expensive social experiments. Second, it highlights how the difference between effective and ineffective is not just between positive benefits and neutral benefits, but between positive benefits and harmful consequences. The tendency in social experiments is to consider a failed implementation as neutral or ineffective, and ignore that it might also be quite harmful to communities and therefore require more rigorous understanding and assessment of the uncertainties involved and how to handle them. Third, it illustrates a case where there are multiple outcomes that need to be considered over time (victim safety and assailant accountability) for the community intervention to be effective overall. Thus the problem here illustrates a case where one must act to respond to the issue, but there are significant uncertainties and risks that cannot be eliminated prior to implementation.

\section{MODEL}

This section provides a brief overview of the model, including the structure of domestic violence caseflows through the criminal justice system and the implementation process of multiple community interventions. The reader is referred elsewhere for a more detailed discussion of the model and its validation (Hovmand et al. 2007, Hovmand et al. in press). The full model is available from the first author.

Figure 1 shows the basic stock-flow structure and feedback mechanisms for the victim arrests model considered in this paper, along with three main community intervention points: mandatory arrests, coordination, and advocacy. Briefly, cases represent intimate partner relationships where there is domestic violence, and what changes the status of a case in this system is who in the relationship is at risk of arrest. Thus, cases enter the system from the left when either the primary aggressor is at risk of arrest or the primary victim is at risk of arrest. Cases then transition through the stock-flow structure at rates influenced by a number of feedback mechanisms as well as the influence of the three main interventions. A key flow in this structure is the crossover mechanism where cases move from Primary aggressor at risk of arrest and has priors to Primary victim at risk of arrest and has no priors. This happens when primary aggressors, for example, learn how to manipulate the system to put the primary victim at risk of arrest. 


\section{Hovmand and Ford}

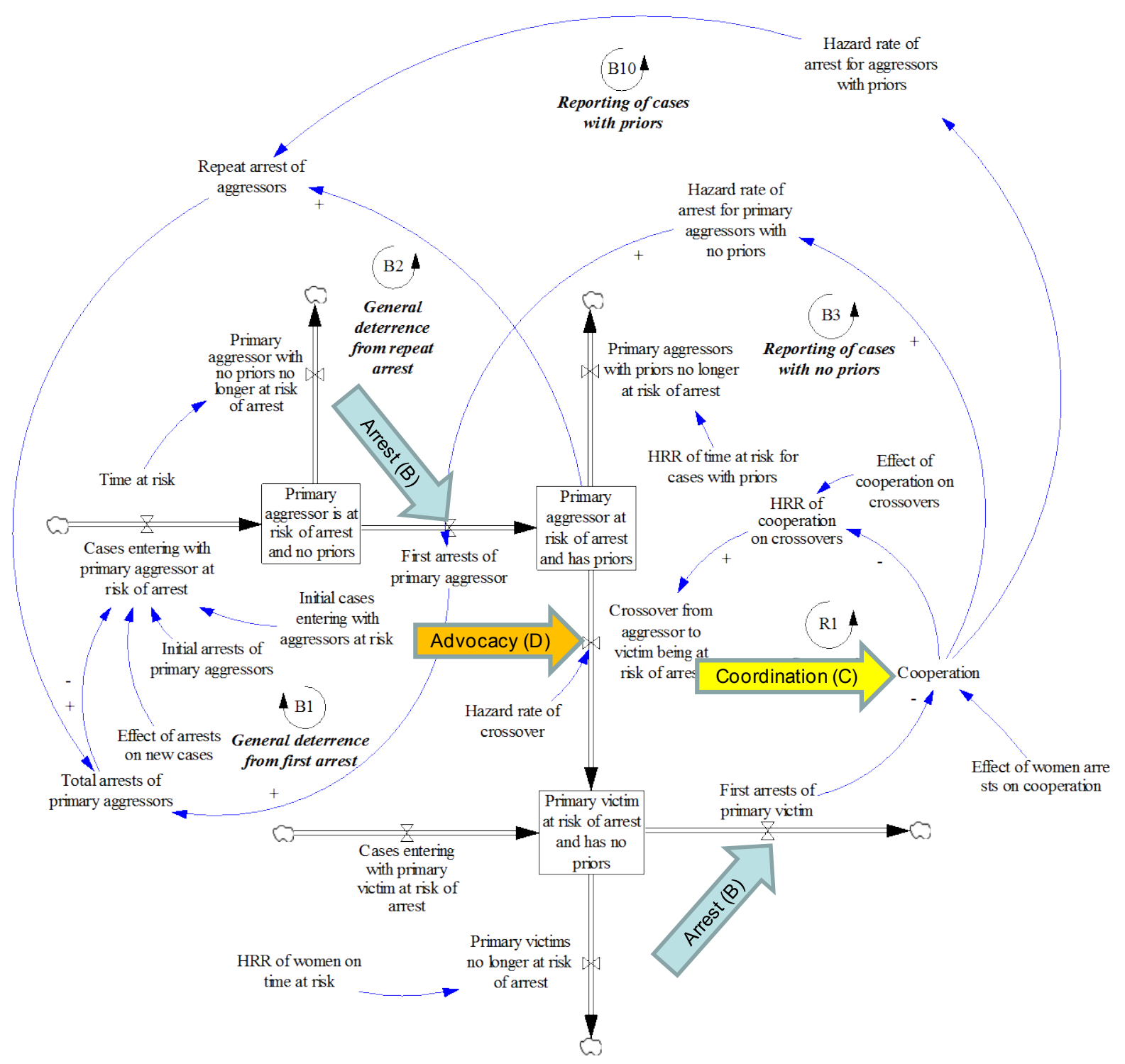

Figure 1: Victim arrests model

The arrest intervention (B) is the mandatory arrest intervention. In this paper, it is assumed that the community has decided to implement the mandatory arrest intervention. This will have two effects. One effect is to move more cases from Primary aggressors at risk of arrest and no priors into the stock Primary aggressor at risk of arrest and has priors, and the second effect is to move cases out of the Primary victim at risk of arrest and has no priors. The coordination intervention (C) represents training of multiple providers in domestic violence response with the goal of improving coordination between providers, in this case, specifically between victim advocates, prosecutors, and law enforcement. When effective, this improves the coordination and reduces the crossover rates. The third intervention is the advocacy intervention (D) where specialized training is provided to the victim advocates and prosecutor's office for working with victims of domestic violence. When effective, this slows the crossover rate.

Figure 2 shows the simulated time series in primary victim arrests after the implementation of a mandatory arrest policy. The simulated time series is generated by the basic stock-flow structure shown in Figure 1. For this set of simulations, we consider two initial phases of behavior. The A phase represents the baseline behavior when the model is a dynamic equilibrium. At year 1 , the mandatory arrest policy is introduced starting the B phase. Figure 2 shows the transient response of the system to the mandatory arrest policy, with an initial and brief decline in victim arrests and then an increase above the initial spike in arrests. The problem behavior of increasing primary victim arrests is the increase above the initial spike, that 


\section{Hovmand and Ford}

is, the region in Figure 2 above the dashed line and shaded in red. The goal is then to develop a strategy for implementing the coordination and advocacy interventions that addresses the problem of increasing victim arrests while also managing the uncertainty in the intervention effectiveness over different communities.

The model assumes that the mandatory arrest policy has been implemented in year 1, and that the implementation processes being modeled involve the coordination intervention and the advocacy intervention. Both of these processes are essentially represented the same way, with a training component, costs associated with the training, actual implementation, and effectiveness determined by both the extent of implementation and the efficacy of the intervention. The coordination training requires staff from multiple agencies to be trained in order to work together. The advocacy intervention only requires a small set of professionals to be trained in specific skills for working with victims of domestic violence. A key assumption in this model is that having been trained does not mean the intervention is implemented, or put differently, to put an intervention into practice presupposes that people have already been trained. For example, a community cannot implement the advocacy training without first training advocates.

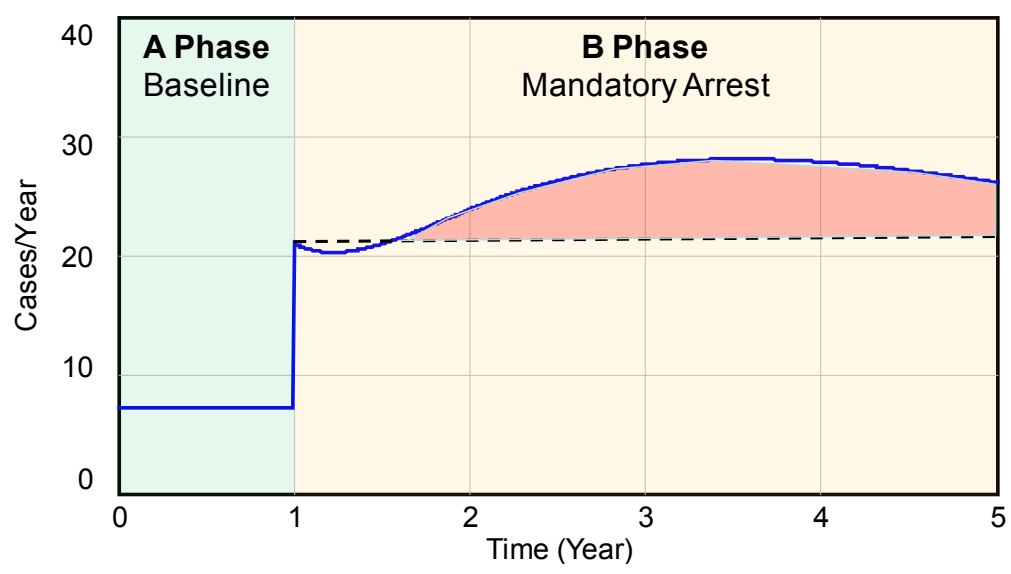

Figure 2: Victim arrests

\section{IMPLEMENTATION STRATEGIES}

Three implementation strategies are considered: a reference strategy and two alternative strategies using the managerial real options approach. To represent these strategies, we found it necessary to develop a formal notation system because the actual implementation in Vensim was cumbersome and error prone.

The resulting system of notation is a modified version of a single subject research design notation where each condition is denoted with a capital letter beginning with the A phase for a baseline phase, and then subsequent intervention phases, i.e., $\mathrm{B}, \mathrm{C}, \mathrm{D}$, etc. The strategy $\mathrm{A}-\mathrm{B}$ then represents a baseline phase with the mandatory arrest phase, $\mathrm{A}-\mathrm{B}-\mathrm{C}$ represents the baseline phase followed by the mandatory arrest phase, which is then followed by the coordination intervention phase $\mathrm{C}$. We denote different sub-phases of interventions using numeric subscripts, so the intervention phase $\mathrm{C}$ can be broken into different phases, $\mathrm{C}_{1}$ and $\mathrm{C}_{2}$ so that $\mathrm{A}-\mathrm{B}-\mathrm{C}_{1} \mathrm{C}_{2}$ is the same as $\mathrm{A}-\mathrm{B}-\mathrm{C}$. Being able to break interventions into subcomponents is useful for identifying and constructing the options. For example, if $\mathrm{C}_{1}$ represents the training component and $\mathrm{C}_{2}$ the implementation of the intervention, we can separate these two activities into distinct phases $\left(\mathrm{A}-\mathrm{B}-\mathrm{C}_{1}-\mathrm{C}_{2}\right)$ or partially implement them in one phase and fully implement them in a second phase $\left(\mathrm{A}-\mathrm{B}-\mathrm{C}_{1}-\mathrm{C}_{1} \mathrm{C}_{2}\right)$. To represent the option and the exercise of the option, we introduce a left-angle-bracket notation to reflect a branch in the implementation strategy conditional on the logic or exercise condition:

$$
S_{1} \equiv A-B C_{1}\left\langle\begin{array}{cl}
B & \text { if arrests decrease } \\
B C_{1} C_{2} & \text { if arrests increase }
\end{array}\right.
$$

This means that we if primary victim arrests decrease (exercise signal), then we do not exercise our option and stay with $\mathrm{B}$, but if primary victim arrests increase (exercise signal), then we do exercise our option by implementing the coordination intervention (exercise decision). The logic of this approach is similar to the use of consort diagrams for representing adaptive research designs, but more compact.

We now move on to formally describe the three strategies considered in this evaluation. The reference strategy defined in (1) involves implementing the mandatory arrest strategy (B) followed by the coordination strategy (C) where the coordination 


\section{Hovmand and Ford}

intervention is divided into two phases, $\mathrm{C} 1$ for training and $\mathrm{C} 2$ for the actual implementation of the coordination intervention. Using our notation, we represent this as:

$$
S_{0} \equiv A-B C_{1} C_{2}
$$

Our first alternative strategy using the real options approach defined in (2) begins with a steady state phase (A), implementation of the mandatory arrest phase (B) and then introduces an option by training practitioners in the coordination intervention $(\mathrm{C} 1)$ without implementing the coordination intervention. This purchases us the option to implement the coordination intervention immediately if the number of victim arrests increases. We represent this as:

$$
S_{1} \equiv A-B C_{1}\left\langle\begin{array}{cl}
B & \text { if arrests decrease } \\
B C_{1} C_{2} & \text { if arrestsincrease }
\end{array}\right.
$$

The second alternative strategy defined in (3) is similar to (2) except now we also consider the uncertainty that the coordination intervention may actually make matters worse. To guard against this, we introduce a second option to switch from the coordination intervention to the advocacy intervention if the number of crossovers begins to increase with the coordination intervention. In traditional real options terminology, this is a nested option because the option to add advocacy is one branch of the option to implement coordination. This is represented as:

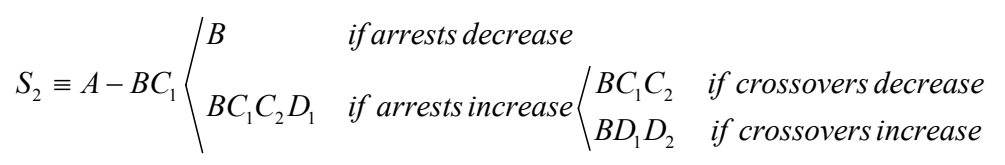

Options include uncertainty, which in this research focuses on the unknown effectiveness of the coordination intervention. Specifically, communities rarely know the strength of an intervention prior to observation. The strength of a psychological or social intervention can be quantified as an effect size (ES) in a variety of equivalent ways. For this research, we assumed that the strength of the community intervention was measured as a standardized difference between the experimental group and comparison group means using Cohen's $d$ as the ES index and took a magnitude of 0.80 to represent a strong positive intervention and -0.80 as a strong harmful intervention (Cohen 1992). A magnitude of 0.80 is equivalent to a difference of 0.80 standard deviations between the experimental and comparison group, which by many considered is a "strong" effect. The uncertainty addressed in this research is the situation where the ES is generally unknown in either its magnitude or polarity. To characterize this uncertainty, the uncertainty of ES is represented as a uniform distribution between -0.80 and +0.80 . Rather than use an actual random uniform distribution, we choose the vector $(-0.8,-0.7,-0.6, \ldots, 0$, $\ldots 0.6,0.7,0.8)$ to simplify checking and analyzing the results. It is important to note, however, that each element in this vector would (a) have an equal probability of being drawn through a random sampling process, and (b) is bounded within the $[-0.8,+0.8]$ interval, and thus maintains the essential characteristics of a uniform random distribution between $[-0.8,+0.8]$.

\section{SIMULATIONS}

To simulate and evaluate each strategy, we ran a sensitivity analysis in Vensim for each strategy with the effectiveness of the coordination intervention varying from harmful to helpful as described previously over two hypothetical communities-a low crime community and a high crime community. The initial level of crime was represented by the number of cases entering the system with primary victims at risk of arrest, which consist of cases where the primary victim may have an outstanding warrant, be possessing or using illegal drugs, carrying a gun without a permit, or engaged in other criminal activity that may lead to an arrest when police respond to a domestic violence call. The initial level of crime for a community is treated as known where the variable Cases entering with primary victim at risk of arrest is varied in the sensitivity analysis with 0 cases per year representing the low crime community and 120 cases per year representing the high crime community. Intermediate values between 0 and 120 cases per year were also tested, but this did not affect the results and so we keep the discussion focused on these two hypothetical communities.

\section{RESULTS}

Table 1 shows the results from the simulating the three strategies over the two types of communities where there is variation in the effectiveness of the coordination intervention. These results are meant to be illustrative of the overall approach and only used to evaluate the potential of the method for further development of the real options approach to implementation strategies. 


\section{Hovmand and Ford}

The results show values for the reduction in victim arrests where positive values indicate larger reductions (and negative values reflect increases in victim arrests) along with the total cost of implementing the intervention. The reduction in victim arrest is represented both in terms of the number of cases and as a percentage of the initial increase. The costs associated with these interventions are essentially training costs. Since the coordination intervention requires professionals from multiple agencies to be trained, this is the most expensive intervention to implement. Costs in this case are calculated by the dollar value of professional time attending these interventions. Such costs are real in the sense that they impact organizations. The advocacy interventions are less expensive because fewer professionals need be trained.

Table 1: Results from simulations of strategies

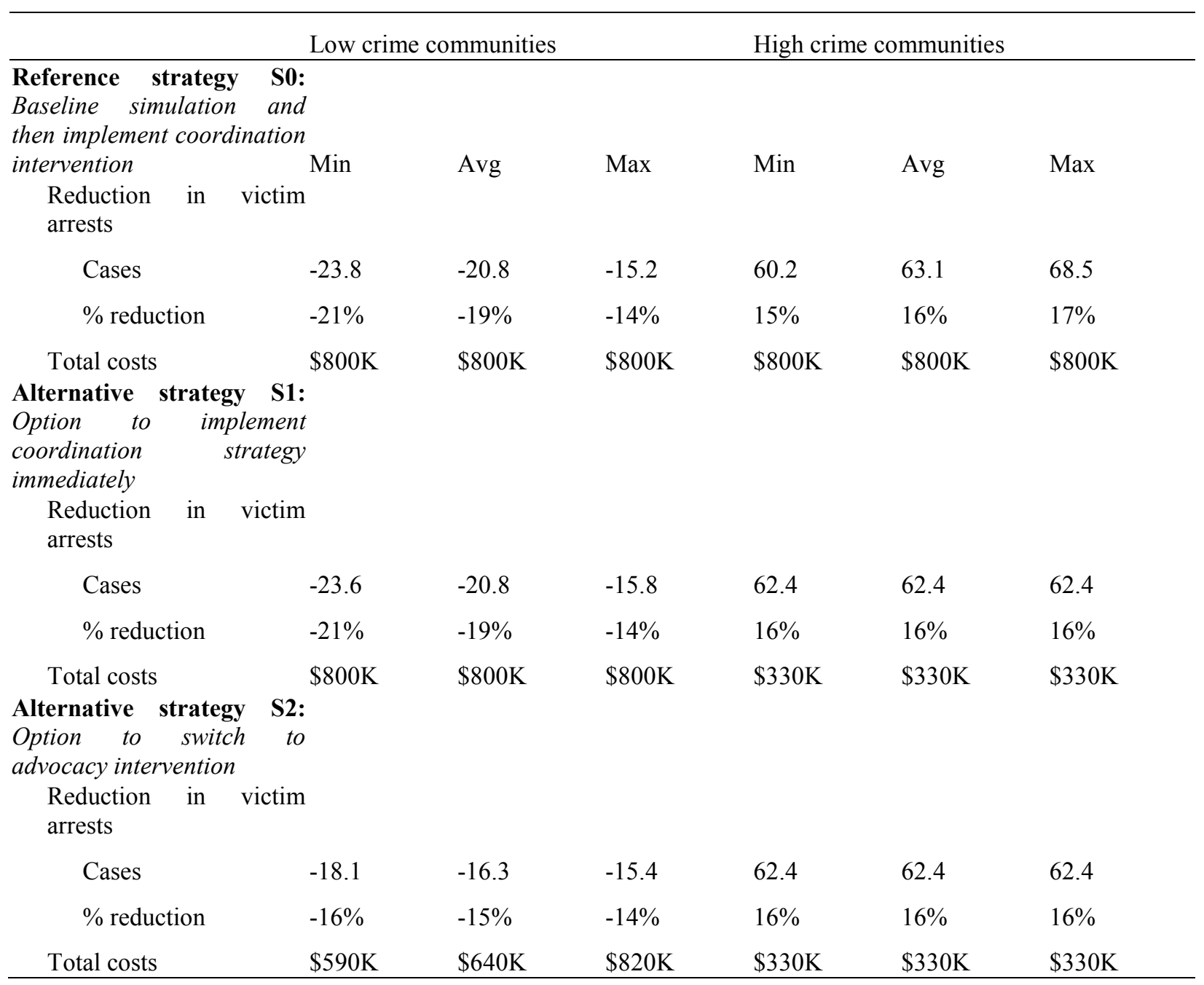

The reference strategy (S0) is the most expensive approach since the coordination intervention is fully implemented in all cases. For low crime communities, the average change in the victim arrests is an increase while high crime communities experience a decrease. The reference strategy provides a basis for comparing the relative benefits of the two other implementation strategies using a real options approach.

The results from the first alternative strategy (S1) show no real differences from the reference strategy for the low crime communities, but better performance for the high crime communities. For high crime communities, there is a reduction in the number of victim arrests, but the strategy is on average likely to cost significantly less. This is because the coordination intervention is only fully implemented if there is an increase in victim arrests. In high crime communities, there will already be a declining trend in victim arrests. As a consequence, the option is not exercised and this essentially saves the community resources. 


\section{Hovmand and Ford}

The results from the second alternative strategy (S2) are more interesting. Here the overall reduction in victim arrests is equal to or better than the reference strategy for both the low and high crime communities, but tends to be on average less expensive for both low and high crime communities.

\section{DISCUSSION AND CONCLUSION}

The primary goal of this paper was to evaluate the potential application of managerial real options to development of implementation strategies. The paper built on prior efforts in product development, and extended the approach to considering social interventions with an application in community responses to domestic violence focusing on mandatory arrest policies. In the course of developing this approach, we found a need to develop a more formal system of notation for representing managerial real options and implementation strategies due to the limitations of how these were actually implemented in Vensim. This system of notation provided a succinct way of describing the implementation strategies while also providing a way to check the actual simulations of each strategy.

Overall, the results show the feasibility of using managerial real options approaches for developing strategies for implementing community interventions. Specifically, using the model to guide the development of options, new strategies were developed that helped mitigate the unintended consequences of the mandatory arrest policy or reduced the total costs of interventions. In particular, we found that we were much more disciplined in developing our implementation strategies and considering where the risks existed in the system, how these risks impacted the outcomes, and began looking much more carefully at how to understand them in terms of the system dynamics model.

The approach also illustrated how combining a managerial real options approach with system dynamics modeling provides a means for thinking through implementation strategies more formally and managing the uncertainty. For example, studying simulations related to the first alternative strategy led to new ideas about how to design the second alternative strategy. We also gained insights into how we might consider restructuring the intervention to better address high crime communities. Overall, the victim advocacy intervention was found to be the more robust intervention in addition to also being the least costly.

A major limitation of real options analysis is decision makers not having a sufficient understanding of the underlying system or the option (Dixit and Pindyck 1994). This has been a problem with conventional real options approach because underlying systems are rarely modeled; only predictions about the projected costs and benefits under varying conditions. Combining the system dynamics modeling, which is an explicit model of the underlying system, with the real options approach makes it much easier to discover flawed assumptions or missing elements in the implementation process. For example, while coordination might have mainly the initial training costs, advocacy is more likely to also involve ongoing salary cost. Some might also question to what extent that having partially implemented a coordination intervention one might be able to discontinue the intervention. We see the explication of such models as a good and necessary step to any planning process involving complex social interventions.

Additionally, we might draw on group model building (e.g., Andersen and Richardson 1997, Richardson and Andersen 1995, Vennix 1996) techniques to help decision makers develop a better understanding of the implementation dynamics and more disciplined strategy for managing the uncertainties in their communities. This could lead to better solutions and consensus among stakeholders about how to respond to social problems, but it might also introduce some additional issues. For example, some might argue that specifying the decisions prior to implementation may actually create incentives or make it possible for individual stakeholders to sabotage interventions for political reasons. While this is certainly possible and should be considered openly among stakeholders, it is also important to realize that this kind of situation goes beyond mere uncertainty and involves a prior level of political conflict that makes any coordinated action difficult. The real options approach developed here is intended as an improved approach to a specific kind of problem, namely, a situation where a community is uncertain about how to proceed with implementing interventions when there might be significant uncertainty about the benefits relative to risks.

Ultimately, it is important to realize that any effort to improve our decision making when we are dealing with dynamic complexity and uncertainty will find itself with a tension between developing disciplined strategies and overly prescriptive approaches that are unjustified given the uncertainty of the system. For example, the very nature of the dynamic complexity in these systems means that it is unlikely that we will be able to use decision rules similar to treatment protocols in medicine or mental health. But, that does not mean that we should not try to develop more disciplined strategies that take into account some of the problems that stakeholders face when managing the implementation of complex social interventions. Perhaps more than ever before, it is important for us to leverage all the tools we have to address the more challenging problems of our day. The real options approach developed here represents one step toward that effort. Such efforts will become increasingly important as practitioners, policy makers, governments, private organizations, and community leaders come to see both the interdependencies of multiple issues and the need to implement multiple interventions to address complex social problems. 


\section{Hovmand and Ford}

\section{ACKNOWLEDGEMENTS}

This work was partially supported through by Center for Mental Health Services Research, George Warren Brown School of Social Work, Washington University; through an award from the National Institute of Mental Health (P30 MH068579).

\section{REFERENCES}

Andersen, D. F. and G. P. Richardson. 1997. Scripts for group model building. System Dynamics Review 13: 107-129.

Avakame, E. F. and J. J. Fyfe. 2001. Differential police treatment of male-on-female spousal violence - Additional evidence on the leniency thesis. Violence against Women 7: 22-45.

Bracher, P. B. 1996. Mandatory arrest for domestic violence: The city of Cincinnati's simple solution to a complex problem. University of Cincinnati Law Review 65: 155-182.

Cohen, J. 1992. A power primer. Psychological Bulletin 112: 155-159.

Dixit, A. K., and R. S. Pindyck. 1994. Investment under uncertainty. Princeton, NJ: Princeton University Press.

Durose, M. R., C. W. Harlow, P. A. Langan, M. Motivans, R. R. Rantala, and E. L. Smith. 2005. Family violence statistics: Including statistics on strangers and acquaintances (No. NCH 207846): Bureau of Justice Statistics, U. S. Department of Justice Office of Justice Programs.

Eigenberg, H., K. McGuffee, P. Berry, and W. H. Hall. 2003. Protective order legislation: Trends in state statutes. Journal of Criminal Justice 31: 411-422.

Eitle, D. 2005. The influence of mandatory arrest policies, police organizational characteristics, and situational variables on the probability of arrest in domestic violence cases. Crime \& Delinquency 51: 573-597.

Ford, D. N. and D. K. Sobek. 2005. Adapting real options to new product development by modeling the second Toyota paradox. IEEE Transactions on Engineering Management 52: 175-185.

Hirschel, D. and E. Buzawa, E. 2002. Understanding the context of dual arrest with directions for future research. Violence against Women 8: 1449-1473.

Hirschel, D. and I. W. Hutchison. 2003. The voices of domestic violence victims: Predictors of victim preference for arrest and the relationship between preference for arrest and revictimization. Crime \& Delinquency 49: 313-336.

Hovmand, P. S., and D. N. Ford. (in press). Sequence and timing of three community interventions to domestic violence. American Journal of Community Psychology.

Hovmand, P. S., D. N. Ford, I. Flom, and S. Kyriakakis. 2007. Women arrested for domestic violence: unintended consequences of mandatory arrest. In Proceedings of the $25^{\text {th }}$ International Conference of the System Dynamics Society and $50^{\text {th }}$ Anniversary Celebration. Boston, MA: System Dynamics Society.

Hovmand, P. S., D. N. Ford, I. Flom, and S. Kyriakakis. (in press). Victims arrested for domestic violence: unintended consequencs of arrest policies. System Dynamics Review.

Hovmand, P. S., and D. F. Gillespie. 2008. Implementation of Evidence Based Practice and Organizational Performance. Journal of Behavioral Health Services \& Research. Available via

<http://www.springerlink.com/content/g263u1x31125613m/>

Kahneman, D., P. Slovic, and A. Tversky. 1982. Judgment under uncertainty: Heuristics and biases. New York: Cambridge University Press.

Klein, K. J., and P. A. Knight. 2005. Innovation implementation: Overcoming the challenge. Current Directions in Psychological Science 14: 243-246.

Mignon, S. I., and W. M. Holmes. 1995. Police Response to Mandatory Arrest Laws. Crime \& Delinquency 41: 430-442.

Mills, L. G. 1998. Mandatory arrest and prosecution policies for domestic violence - A critical literature review and the case for more research to test victim empowerment approaches. Criminal Justice and Behavior 25: 306-318.

Pfeffer, J., and R. I. Sutton. 2000. The knowing-doing gap. Boston, MA: Harvard Business School Press.

Repenning, N. P. 2002. A simulation-based approach to understanding the dynamics of innovation implementation. Organization Science 13: 109-127.

Richardson, G. P., and D. F. Andersen. 1995. Teamwork in group model building. System Dynamics Review 11: 113-137.

Samuel, Y., and C. Jacobsen, 1997. A system dynamics model of planned organizational change. Computational and mathematical organization theory 3: 151-171.

Sherman, L. W., and R. A. Berk. 1984. The specific deterrent effects of arrest for domestic assault. American Sociological Review 49: 261-272.

Vennix, J. 1996. Group model building. New York: John Wiley \& Sons.

Wanless, M. 1996. Mandatory arrest: A step toward eradicating domestic violence, but is it enough? University of Illinois Law Review 2: 533-587. 


\section{AUTHOR BIOGRAPHIES}

PETER S. HOVMAND is director of the Social System Design Lab at the George Warren Brown School of Social Work, Washington University. His PhD. is from Michigan State University in 2003. He teaches system dynamics modeling and design of sustainable social policies and programs. His research interests include innovation implementation, organizational behavior, participatory methods for model building, and domestic violence. His email is <phovmandewustl. edu>.

DAVID N. FORD is an associate professor in the Zachry Department of Civil Engineering at Texas A\&M University. He received his Ph.D. from Massachusetts Institute of Technology in 1995. He teaches strategic engineering management and construction management. His research interests include managerial real options, development project dynamics, risk management, and the management of engineering consultants. His email is <davidfordetamu.edu>. 